\title{
De re tenses and trace conversion*
}

\author{
Moshe E. Bar-Lev \\ The Hebrew University of Jerusalem
}

\begin{abstract}
I suggest a quantificational account for tenses in which the seemingly peculiar behavior of tenses that are interpreted de re (most notably the double access reading of English present-under-past sentences) falls out from a general Trace Conversion rule that applies to moved quantifiers, as in Fox 2002. I propose that $d e$ $r e$ tenses involve movement (following Ogihara 1989), and that the first argument of tenses is a property of times which characterizes the set of times that include the local evaluation time, such that the application of Trace Conversion to moved tenses yields an inclusion requirement with respect to the local evaluation time of the base position. Unlike previous analyses (Ogihara 1989; Abusch 1997), the current analysis predicts that a de re interpretation of a tense (past or present) involves inclusion of the attitude time. This is supported by the availability of simultaneous readings for past-under-past sentences in non-SOT languages such as Hebrew, and the unavailability of 'mixed' (simultaneous and backward-shifted) readings for past-under-past constructions under universal quantification.
\end{abstract}

Keywords: semantics of tense, quantification, trace conversion, de re, sequence of tense, double access, Hebrew

\section{Introduction}

Cases where embedded tenses seem to be interpreted de re, namely indexically, are puzzling from the point of view of the semantics of tenses. The problem has been mostly noted for the double access reading of English present-under-past sentences like (1): Whenever a tense is interpreted as indexical, it seems that it also contributes a relative meaning, as if it were both an indexical and a relative tense at the same time. Intuitively, the embedded tense in (1) says something both about the speaker's

* This paper is based on my MA thesis which was supervised by Nora Boneh, to whom I am grateful for very helpful discussions and comments on various stages of this work. I have benefited a lot from discussions with Daniel Altshuler, Elitzur Bar-Asher Siegal, Luka Crnič, Danny Fox, Yosef Grodzinsky, Yael Sharvit, Itai Bassi, David Kashtan and Daniel Margulis. Thanks to all the faculty and students at the Language, Logic and Cognition Center, to the participants at the SOT meetings held at the LLCC and to the audiences and abstract reviewers of SALT 25, GLOW 38, the linguistics colloquium at Ben-Gurion University and the linguistics colloquium at Tel Aviv University. All mistakes are my own. The research was partly funded by ISF grant 1366/14 to Nora Boneh.

(C2015 Bar-Lev 
"now", the utterance time, hence indexical meaning; and about John's "now", the attitude time, hence relative meaning. However, there has been disagreement about the nature of that relative meaning.

John thought that Mary is pregnant.

This paper aims to argue that under close scrutiny it can be seen that the relative component that de re tenses contribute is a kind of present. That is, de re tenses contribute a relative meaning of inclusion of the attitude time. A further claim that will be made here is that this puzzling behavior teaches us something about the semantics of tenses: that they are quantificational, and that they quantify over the set of times that include the local evaluation time. Together with an independently needed Trace Conversion rule for the syntax-semantics interface (following Fox 2002), this enables us to predict that whenever a tense moves, its lower copy is interpreted as a definite description which presupposes inclusion of its local evaluation time. And since de re readings of tenses will be analyzed (following Ogihara 1989) as involving movement, the relative meaning of inclusion for de re tenses will be predicted.

The paper is structured as follows: In Section 2 I present the problem with the analysis of double access, and the idea that it is an instance of de re interpretation of tenses. In Section 3 I present my analysis which is based on Trace Conversion. In Section $4 \mathrm{I}$ argue that the current proposal fares better than previous de re analyses of tenses, in light of de re interpretations of past-under-past sentences. I show that the proposed analysis predicts that every de re tense contributes a relative meaning of inclusion of the attitude time (Section 4.1), and support this prediction by the availability of simultaneous readings for past-under-past sentences in non-SOT languages such as Modern Hebrew (Section 4.2), and the unavailability of 'mixed' (simultaneous and backward-shifted) readings for past-under-past structures under universal quantification (Section 4.3). Section 5 summarizes and discusses some problems and an alternative analysis.

\section{Double access}

\subsection{Data}

A present complement clause embedded under a past attitude verb in English, as in (1), has only the double access reading (DAR). DAR requires the embedded event not only to hold at the attitude time (AT = the local evaluation time of the embedded clause, John's "now" in (1)) but to encompass the utterance time (UT = the local evaluation time of the matrix clause, the speaker's "now" in (1)) too. ${ }^{1}$

1 This is not an exact characterization of DAR, but it suffices for the discussion. For detailed discussions about the nature of DAR see Ogihara 1989; Abusch 1997; Bary \& Altshuler 2015; Klecha 2014. 
Starting out from the assumption that tenses are always relative - namely that they are evaluated with respect to the local evaluation time of the clause in which they appear - this is surprising: Why would the event in the embedded clause 'care' about the utterance time at all? This is illustrated in (2).

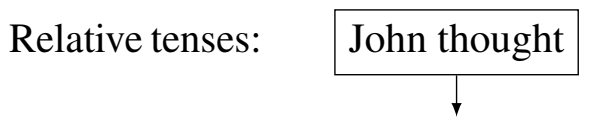

Utterance time (UT)

the speaker's "now"

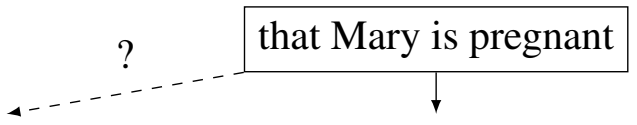

Attitude time (AT)

John's "now"

In order to see that the utterance time plays a crucial role in the interpretation of sentences such as (1), consider the following well-observed contrast:

Double access:

a. Yesterday, John thought that Mary is pregnant.

b. \#Two years ago, John thought that Mary is pregnant.

Presumably, (3b) is infelicitous since it posits a requirement on the time of which John believed Mary's pregnancy to hold that clashes with our world knowledge in which human pregnancies cannot last two years.

If so, assuming that the embedded present in (1) is simply relative we are not able to explain how the utterance time becomes relevant to the running time of the embedded event. On the other hand, assuming that it is indexical, namely evaluated with respect to the utterance time, won't be enough either. We would just replace the question of how the utterance time is relevant for the embedded event with the question of how the attitude time is relevant for it.

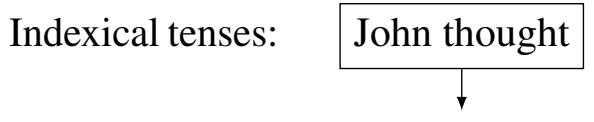

Utterance time (UT) the speaker's "now"

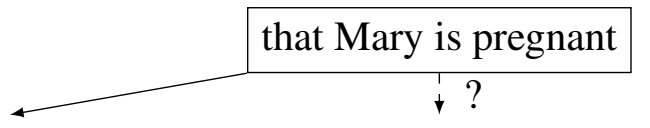

Attitude time (AT)

John's "now"

That the attitude time cannot be ignored in the interpretation of (1) can be seen in that (1) has no reading along the lines of (5).

John thought that Mary would be pregnant now.

On the face of it, there are two ways to treat the embedded present in (1), as indexical or as relative, but neither is adequate on its own. That is, in order to account for the DAR of present-under-past sentences like (1), two things should be derived: (i) an indexical component for DAR, namely sensitivity of the embedded event to UT, and (ii) a relative component for DAR, namely sensitivity of the embedded event to AT. 
De re tenses and trace conversion

\subsection{De re approaches}

A common approach to facing this problem, mainly due to Ogihara (1989) and Abusch (1997), is that the embedded present in (1) is interpreted de re. ${ }^{2}$ Put simply, it is an indexical tense. However, as we have seen this only gives us the means to provide an indexical component for DAR. But what about a relative component?

Two main answers were given to this question within de re analyses of DAR: one by Abusch (1997), and the other by Ogihara (1989). For now I will only briefly describe their answers, and in Section 4 I will discuss them in somewhat more detail.

Abusch's answer is that there is a general restriction on the interpretation of tenses which she calls the Upper Limit Constraint (ULC). Following Heim's (1994) implementation, it prohibits assigning to a tense node a time that is later than its local evaluation time.

Assuming that the embedded present in (1) is a de re tense, the ULC entails effectively that (1) can only be felicitous if John thought of Mary's pregnancy time as being before or including his "now", i.e., if it is not interpreted as being after AT.

However, the ULC-based approach faces some conceptual as well as empirical problems. One empirical problem will be discussed in Section 4.3. For now I will only point out the conceptual problems it raises. First, the ULC is an ad hoc constraint. Even though it provides a relative component for de re tenses, it is not clear what other motivation this kind of formal constraint might have. Second, the ULC forces us to treat future as something different than present and past - i.e., not as a tense - since future gives us a time that is later than the local evaluation time, which is what the ULC prevents. Even though saying that future is not a tense might not be such a bad idea, the ULC leaves us no other option and as such it limits our theoretical possibilities.

Escaping these kinds of problems and not utilizing the dubious ULC, Ogihara's (1989) Copy-based approach suggests the DAR is the result of tense movement that leaves a copy, which is in line with the Copy theory of movement.

Following Ogihara (1989), I will suggest that de re tenses are the result of movement that leaves a copy in the embedded clause. The higher copy of the tense provides an indexical component, and the lower copy is responsible for a relative component for de re tenses.

The claim that I put forward in this paper is that the lower copy of de re tenses provides a relative component which requires the embedded event to include the attitude time. This generalizes to any de re interpretation of tenses, even de re past tense. The generalization is in (6).

2 I set aside the question of what makes the de re interpretation of the embedded present in (1) obligatory, which seems to be a mystery. See Abusch 1997 and Klecha 2014. 
INCLUSION GENERALIZATION:

A de re tense is interpreted as including the local evaluation time of its base position (AT).

Section 3 presents an analysis that predicts (6). Section 4 adduces evidence in favor of (6).

\section{Proposal: A Trace-Conversion-based approach}

We have seen that de re approaches suggest that the embedded present in presentunder-past sentences is interpreted de re, and that Ogihara suggested that this interpretation comes about by movement, such that the higher copy provides an indexical component and the lower copy is responsible for a relative component. The goal of this section is to motivate and provide an analysis in which the interpretation of the lower copy of de re tenses is always the same: They are interpreted as a definite description that presupposes inclusion of the attitude time, thus conforming to (6).

\subsection{Trace Conversion for quantificational tenses}

As a first step towards an analysis, I want to present an interpretability problem that arises if we assume that tenses are quantificational, that they may be interpreted de re, and that de re tenses involve copy movement as in Ogihara's Copy-based approach. Then I present my analysis that solves that problem using Trace Conversion and the assumption that tenses quantify over the set of times that include the local evaluation time. Later I show that the proposed analysis also predicts (6).

There is a long standing debate whether tenses are to be analyzed as quantificational or as pronominal, namely as referring expressions. Partee (1973) has claimed that tenses should be treated as pronominal since they behave as if they refer to times. However, Stalnaker (as cited by von Fintel \& Heim 2011), and later Ogihara (1989) proposed that tenses are still quantificational and that similarly to other quantifiers they quantify over a contextually provided domain of times. ${ }^{3}$

Let us assume a quantificational semantics for tenses. The question that this section discusses is this: Given this assumption, and the assumption that tenses can move and leave a copy behind as in Ogihara's Copy-based approach, then what is the interpretation of a tense, i.e., a temporal quantifier, that has copies in two different places in a single LF?

Specifically, take the LF of (1) in which the embedded present has moved to get a de re interpretation. In the Copy-based approach, a copy is left behind as in (7).

3 In the following discussion I neglect the contextual restriction, which does not play a crucial role here. 
De re tenses and trace conversion

What is the interpretation of such an LF?

$\underline{\mathrm{PRES}_{3}} \lambda 7 \mathrm{PAST}_{1}$ John think $\underline{\mathrm{PRES}_{7}}$ Mary be-pregnant

This relates to a general problem with the interpretation of quantifiers that move within the Copy theory of movement: If we want to account for the reading of (8) where every girl takes higher scope than a boy we would want to move every girl up as in (8a). But leaving a full copy of a quantifier phrase of type $\langle e t, t\rangle$ in two places in the structure yields an uninterpretable structure. The Trace Conversion rule suggested by Fox (2002), in (9), is designed to solve such problems. It converts the lower copy into a definite description of type $e$, as in (8b).

A boy kissed every girl.

a. ?every girl $\lambda 1$ a boy kissed [every girl $]_{1}$

b. every girl $\lambda 1$ a boy kissed [the girl $\underline{1}]$

TRACE CONVERSION:

a. Variable Insertion (VI): (Det) Pred $\rightarrow$ (Det) [Pred $\lambda y(y=x)]$

b. Determiner Replacement (DR):

(Det) [Pred $\lambda y(y=x)] \rightarrow$ the [Pred $\lambda y(y=x)]$

(Fox 2002: 67)

The exact same problem with the interpretation of (8a) would apply to structures such as in (7), if tenses are quantifiers, that is, if the type of $\mathrm{PRES}_{7}$ is $\langle i t, t\rangle .{ }^{4} \mathrm{~A}$ natural move is to apply Trace Conversion to (7) too. Unfortunately, it turns out that the Trace Conversion rule cannot be applied to quantificational tenses as usually defined. Consider a simple quantificational tense semantics as in (10).

$$
\begin{array}{ll}
\text { a. } & \llbracket \mathrm{PRES} \rrbracket\left(t_{i}\right)\left(P_{\langle i, t\rangle}\right)=1 \text { iff } \exists t^{\prime}\left[t^{\prime} \supseteq t \wedge P\left(t^{\prime}\right)=1\right] \\
\text { b. } & \llbracket \operatorname{PAST} \rrbracket\left(t_{i}\right)\left(P_{\langle i, t\rangle}\right)=1 \text { iff } \exists t^{\prime}\left[t^{\prime}<t \wedge P\left(t^{\prime}\right)=1\right]
\end{array}
$$

An immediate problem arises: The first argument of tenses in (10) is a time and not a property of times, unlike nominal quantifiers. Applying the Trace Conversion rule in such a case wouldn't do any good: The converted quantifier would end up meaning something like "the today", since the argument of the would be a time rather than a property of times.

The question can be asked as follows: If tenses are quantifiers, just as nominal quantifiers, why do they take a time and not a property of times? What is the reason

4 In Ogihara 1989 this problem is avoided by assuming that quantification is not part of the core semantics of tenses, but rather tenses are properties of times/states, and existential closure is done higher up. Additionally, his proposal is based on a Davidsonian approach with reference to states, which he claims provides the right results for capturing the tricky DAR associated with present-underpast sentences. To keep the presentation traceable I only use his Copy movement idea, similarly to what has been done in Ogihara \& Sharvit 2012. 
that nominal quantifiers are of type $\langle e t,\langle e t, t\rangle\rangle$ whereas temporal quantifiers are of type $\langle i,\langle i t, t\rangle\rangle$ rather than $\langle i t,\langle i t, t\rangle\rangle$ ?

Therefore, I submit that tenses are indeed of type $\langle i t,\langle i t, t\rangle\rangle$, similarly to nominal quantifiers. What should be the property they quantify over? There are a few possibilities here. I suggest that this is the property of including the local evaluation time, since that property would let us predict (6).

I use a predicate $\mathscr{T}$, a function of type $\langle i, i t\rangle$, which is defined as follows.

$$
\llbracket \mathscr{T} \rrbracket=\lambda t \cdot \lambda t^{\prime} \cdot t^{\prime} \supseteq t
$$

$\mathscr{T}$ takes the local evaluation time as its argument. Given a local evaluation time $t$, $\llbracket \mathscr{T} \rrbracket(t)$ is the characteristic function of the set of all times that include $t$.

$$
\llbracket \mathscr{T} \rrbracket(t)=\lambda t^{\prime} \cdot t^{\prime} \supseteq t
$$

The kind of function given by $\llbracket \mathscr{T} \rrbracket(t)$ is a suitable candidate for a predicate to be taken by the temporal quantifier. What the quantifiers take is a predicate of type $\langle i, t\rangle$ : a property of times, which is the property of including the evaluation time.

Before we discuss the way in which the semantics of tenses should be amended in order to work with this kind of argument, note that the application of Trace Conversion to tenses is now possible. Since all tenses take the property of including the evaluation time as their argument - that is, an argument which very much resembles a present tense - the application of Trace Conversion would strip them of their inherent meanings and leave intact only the 'presentness' of their argument.

Assume that we have a structure with a present tense, the first argument of which is [ $\mathscr{T} t^{*}$ ], namely the set of times that include the utterance time, as in (13a). After QRing it as in (13b), we can apply Trace Conversion in (13c) and (13d), to derive the meaning of the lower copy, which is now of type $i$, as in (13e).

$$
\begin{array}{llr}
\text { a. } & \ldots\left[{ }_{\phi} \text { PRES }\left[\mathscr{T} t^{*}\right]\right] \ldots & \\
\text { b. } & {\left[\operatorname{PRES}\left[\mathscr{T} t^{*}\right]\right] \lambda x \ldots\left[{ }_{\phi} \text { PRES }\left[\mathscr{T} t^{*}\right]\right] \ldots} & \text { QR } \\
\text { c. } & {\left[\operatorname{PRES}\left[\mathscr{T} t^{*}\right]\right] \lambda x \ldots\left[{ }_{\phi} \text { PRES }\left[\left[\mathscr{T} t^{*}\right] \lambda y(y=x)\right]\right] \ldots} & \text { VI } \\
\text { d. } & {\left[\operatorname{PRES}\left[\mathscr{T} t^{*}\right]\right] \lambda x \ldots\left[{ }_{\phi} \text { the }\left[\left[\mathscr{T} t^{*}\right] \lambda y(y=x)\right]\right] \ldots} & \text { DR } \\
\text { e. } & \llbracket \phi \rrbracket=\text { the } t \text { s.t. } t \supseteq t^{*} \text { and } t=x &
\end{array}
$$

The meaning we get for the lower Copy after Trace Conversion in (13e) is independent of whether it was a past or a present to begin with: Since Trace Conversion replaces the tense with the, the same result of inclusion would be achieved if it were a past tense. This seemingly strange result is what lets us predict (6), and it will become crucial later, when we discuss past-under-past sentences (Section 4).

I suggest the semantics of tenses in (14). 
De re tenses and trace conversion

$$
\begin{array}{ll}
\text { a. } & \llbracket \text { PRES } \rrbracket\left(T_{\langle i, t\rangle}\right)\left(P_{\langle i, t\rangle}\right)=1 \text { iff } \exists t[T(t) \wedge P(t)=1] \\
\text { b. } & \llbracket \text { PAST } \rrbracket\left(T_{\langle i, t\rangle}\right)\left(P_{\langle i, t\rangle}\right)=1 \text { iff } \exists t\left[\exists t^{\prime}\left[T\left(t^{\prime}\right) \wedge t<t^{\prime}\right] \wedge P(t)=1\right]
\end{array}
$$

I assume that tenses are relative: $\mathscr{T}$ takes the local evaluation time as its argument, and the result of applying $\mathscr{T}$ to the local evaluation time, namely the set of times that include the local evaluation time, is what tenses take as their first argument ( $T$ in $(14))^{5}$

Given the set of times that include the local evaluation time, the definition of PRES in (14a) is simple: It yields truth in case there is a time which is within this set and the given proposition is true at that time. The definition of PAST in (14b), given such a set, is more complex: It yields truth in case there is a time $(t)$ which is before some time $\left(t^{\prime}\right)$ within this set, and the proposition is true at that time $(t) .^{6}$

Before deriving the puzzling DAR of (1), let us see how this works in simple cases. I assume a system in which world and time variables are represented in the syntax, and predicates and clauses are of type $\langle s, i t\rangle$ (cf. Percus 2000; Kusumoto 2005). Truth for utterances is defined as in (15), following von Fintel \& Heim's (2011: 104) definition, modified to incorporate times: ${ }^{7}$

$$
\text { An utterance of a sentence } \phi \text { in world } w \text { at time } t \text { is true iff } \llbracket \phi \rrbracket(w)(t)=1 \text {. }
$$

A tenseless clause such as "Mary be-pregnant" has the representation in (16).

$$
\lambda w_{1} \lambda t_{1} \text { Mary be-pregnant } w_{1}, t_{1}
$$

Not having tenses, the world and time arguments taken by the predicate be-pregnant

5 For any evaluation time $t_{i}$ there is a unique function $T_{i}$ such that $T_{i}=\llbracket \mathscr{T} \rrbracket\left(t_{i}\right)$, which is the argument of tenses whenever they appear in a position where $t_{i}$ is the local evaluation time. Therefore in simple cases (i.e., when no movement is involved) the definitions of tenses in (14) give equivalent results to the standard definitions in (10), since the equivalences in (i) hold:

(i) Given a local evaluation time $t_{i}$ and the function $T_{i}$ s.t. $T_{i}=\llbracket \mathscr{T} \rrbracket\left(t_{i}\right)$ :

$$
\begin{array}{ll}
\text { a. } & \exists t\left[T_{i}(t) \wedge P(t)\right] \Leftrightarrow \exists t\left[t \supseteq t_{i} \wedge P(t)\right] \\
\text { b. } \quad \exists t\left[\exists t^{\prime}\left[T_{i}\left(t^{\prime}\right) \wedge t<t^{\prime}\right] \wedge P(t)\right] \Leftrightarrow \exists t^{\prime}\left[t^{\prime}<t_{i} \wedge P\left(t^{\prime}\right)\right]
\end{array}
$$

6 This definition of PAST renders it a non-conservative quantifier. See Section 5.

7 I choose such a system mainly for convenience. The desired results can be derived otherwise, for example utilizing a distinguished variable 0 for the local evaluation time, as in Heim 1994. This requires some modifications, see footnote 8 .

Additionally, the semantics I assume for think is in (ii).

$$
\begin{aligned}
\llbracket \operatorname{think} \rrbracket(w)(t)\left(P_{<s, i t>}\right)(x)= & 1 \operatorname{iff} \forall\left\langle w^{\prime}, t^{\prime}\right\rangle \in \operatorname{Dox}_{x}(w, t): P\left(w^{\prime}\right)\left(t^{\prime}\right)=1 \\
& \text { Where } \operatorname{Dox}_{x}(w, t) \text { is the set of doxastic alternatives of } x \text { in } w \text { at } t .
\end{aligned}
$$


are bound by the local evaluation world and time $-w_{1}$ and $t_{1}$.

A tensed clause as in (17a) has the structure in (17b) and the truth conditions (given the actual world $w^{*}$ and the utterance time $t^{*}$ ) in (18).

a. Mary was pregnant.

b. $\lambda w_{1} \lambda t_{1}\left[\operatorname{PAST}\left[\mathscr{T} t_{1}\right]\right] \lambda t_{3}$ Mary be-pregnant $w_{1, t_{3}}$

$\llbracket(17 \mathrm{~b}) \rrbracket\left(w^{*}\right)\left(t^{*}\right)=1$ iff

$\exists t\left[\exists t^{\prime}\left[t^{\prime} \supseteq t^{*} \wedge t<t^{\prime}\right] \wedge\right.$ Mary be-pregnant in $w^{*}$ at $\left.t\right]$ iff

$\exists t\left[t<t^{*} \wedge\right.$ Mary be-pregnant in $w^{*}$ at $\left.t\right]$

\subsection{Application - de re tenses in present-under-past sentences}

We can now show how the DAR can be derived for (1). First, the embedded PRES together with its first argument undergo QR, as in (19a). Since they appear in the scope of two different local evaluation times, the two copies are not completely identical: In the lower copy the argument of $\mathscr{T}$ is $t_{3}$ which corresponds to AT, whereas in the higher copy the argument of $\mathscr{T}$ is $t_{1}$ which corresponds to UT. ${ }^{8}$

Second, the application of Trace Conversion to the lower copy yields the interpretable structure in (19b). The truth conditions of (19b) given the actual world and the utterance time are in $(19 \mathrm{c})$.

John thought that Mary is pregnant.

$$
\begin{aligned}
& \text { a. } \mathrm{QR} \text { : } \\
& \left.\left.\left.\left.\lambda w_{1} \lambda t_{1} \text { [PRES [ } \mathscr{T} t_{1}\right]\right] \lambda t_{7} \text { [PAST [ } \mathscr{T} t_{1}\right]\right] \lambda t_{2} \text { John think } w_{w_{1}, t_{2}} \\
& \lambda w_{3} \lambda t_{3}\left[\operatorname{PRES}\left[\mathscr{T} t_{3}\right]\right] \lambda t_{4} \text { Mary be-pregnant } w_{3}, t_{4} \\
& \text { b. Trace Conversion: } \\
& \left.\left.\left.\lambda w_{1} \lambda t_{1} \text { [PRES [ } \mathscr{T} t_{1}\right]\right] \lambda t_{7} \text { [PAST }\left[\mathscr{T} t_{1}\right]\right] \lambda t_{2} \text { John think } w_{w_{1}, t_{2}} \\
& \left.\left.\left.\lambda w_{3} \lambda t_{3} \text { [the [[ } \mathscr{T} t_{3}\right] \lambda y \cdot y=t_{7}\right]\right] \lambda t_{4} \text { Mary be-pregnant } w_{3}, t_{4} \\
& \text { c. } \llbracket(19 \mathrm{~b}) \rrbracket\left(w^{*}\right)\left(t^{*}\right)=1 \text { iff } \\
& \underline{\exists t^{\prime \prime}\left[\underline{t}^{\prime \prime} \supseteq t^{*}\right.} \wedge \exists t^{\prime}\left[t^{\prime}<t^{*} \wedge \forall\langle w, t\rangle \in \operatorname{Dox}_{J o h n}\left(w^{*}\right)\left(t^{\prime}\right):\right. \\
& \text { Mary be-pregnant in } \left.w \text { at the } t^{\prime \prime \prime} \text { s.t. } t^{\prime \prime \prime} \supseteq t \text { and } t^{\prime \prime \prime}=t^{\prime \prime}\right] \text { ] }
\end{aligned}
$$

The LF in (19a) corresponds to the desired double access meaning. The relative

8 A potential advantage of using the distinguished variable 0 for the local evaluation time (see footnote 7 ), is that there would be no need to assume copies which are not identical as in (19), a situation which has no equivalent in the nominal domain. This requires replacing the first argument of tenses with

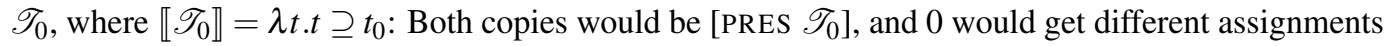
depending on the clause in which it appears. Such a move requires the further assumption that the local evaluation time has a special status, i.e., that $\lambda$-abstraction over it is not created by QR. This is what is assumed by von Stechow's (1995) QR CONVENTION: "The movement index created by QR is always different from the distinguished index 0". I thank Uli Sauerland for highlighting this issue. 
component of DAR is the result of the converted copy downstairs, because of which the pregnancy time believed by John is presupposed to include AT, i.e., John's "now"; and the indexical component of DAR is asserted by the higher copy: The time of which John believed Mary to be pregnant is extensionally required to include UT. ${ }^{9}$

Just like in Ogihara's original Copy-based approach, both the indexical component and the relative component of DAR encode inclusion. In the next section, which is dedicated to a comparison of the current proposal to previous ones in light of past-under-past sentences, we will see that the two approaches can be teased apart when considering such sentences.

\section{Substantiation for the analysis: Comparison with previous de re accounts}

In this section I consider how the current proposal fares with respect to other de re accounts. Past-under-past sentences are added to the picture as a way to differentiate the predictions of the various accounts, and to claim that (6) is the right prediction.

\subsection{Setting the scene: Predictions for de re past-under-past sentences}

It has been long observed (Jespersen 1924; Ogihara 1989; Abusch 1997; a.o.) that a past complement clause embedded under a past attitude verb (past-under-past as in (20)) in English can have either a backward-shifted reading as in (20a) or a simultaneous reading as in (20b). This is known as Sequence of Tense (SOT).

John thought that Mary was pregnant.

a. John thought: "Mary was pregnant". Backward-shifted reading

b. John thought: "Mary is pregnant". Simultaneous reading

I do not deal here directly with explaining the existence of these two readings. Instead, I focus on the predictions of the various de re analyses for tenses as to the de re interpretation of past-under-past sentences. First I will go over the prediction of the current proposal, and then compare it to the predictions of previous analyses.

Recall that the meaning we get for the lower copy in (19) after Trace Conversion is independent of whether it was PAST or PRES to begin with: Since Trace Conversion replaces the tense with the, the same result of inclusion for the lower copy would be achieved if it were a past tense. This is the case in (21) which is the de re LF of (20).

9 An anonymous reviewer claims that as it stands, the truth conditions in (19) are not quite right: Since $t_{7}$ appears within the attitude context and bound from outside, it yields a belief of John about a time that includes the utterance time. However, it is clear that the attitude holder should not have any belief directly about the utterance time. I hope this can be solved using a concept-generator mechanism as in Percus \& Sauerland 2003 and Charlow \& Sharvit 2014 and applying it to the lower copy, such that the belief is about a time concept applied to $t_{7}$ rather than about $t_{7}$ itself. 


$$
\begin{aligned}
& \text { a. } \quad \mathrm{QR} \text { : } \\
& \left.\left.\left.\left.\lambda w_{1} \lambda t_{1} \text { [PAST [ } \mathscr{T} t_{1}\right]\right] \lambda t_{7} \text { [PAST [ } \mathscr{T} t_{1}\right]\right] \lambda t_{2} \text { John think } w_{w_{1}, t_{2}} \\
& \lambda w_{3} \lambda t_{3}\left[\text { PAST }\left[\mathscr{T} t_{3}\right]\right] \lambda t_{4} \text { Mary be-pregnant } w_{w_{3}, t_{4}} \\
& \left.\left.\left.\left.\lambda w_{1} \lambda t_{1} \text { [PAST [ } \mathscr{T} t_{1}\right]\right] \lambda t_{7} \text { [PAST [ } \mathscr{T} t_{1}\right]\right] \lambda t_{2} \text { John think } w_{w_{1}, t_{2}} \\
& \lambda w_{3} \lambda t_{3}\left[\text { the }\left[\left[\mathscr{T} t_{3}\right] \lambda y \cdot y=t_{7}\right]\right] \lambda t_{4} \text { Mary be-pregnant } w_{3}, t_{4} \\
& \text { c. } \llbracket(21 \mathrm{~b}) \rrbracket\left(w^{*}\right)\left(t^{*}\right)=1 \text { iff }
\end{aligned}
$$

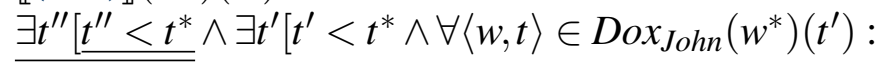

$$
\begin{aligned}
& \text { Mary be-pregnant in } \left.\left.w \text { at the } t^{\prime \prime \prime} \text { s.t. } t^{\prime \prime \prime} \supseteq t \text { and } t^{\prime \prime \prime}=t^{\prime \prime}\right]\right]
\end{aligned}
$$

Crucially, the only place where there is a difference between the truth conditions in (19c) and (21c) is the doubly-underlined $t^{\prime \prime}<t^{*}$ in (21c) which replaces the $t^{\prime \prime} \supseteq t^{*}$ in $(19 \mathrm{c})$. The current proposal thus predicts that the truth conditions of the de re structures of (20) and (1) would be identical except for the temporal relation with respect to UT, namely the indexical component. On the other hand, the relative component in both de re past-under-past and de re present-under-past requires inclusion. This is exactly what is required for predicting (6), repeated here:

\section{INCLUSION GENERALIZATION:}

A de re tense is interpreted as including the local evaluation time of its base position (AT).

This result comes about given our assumptions: (i) that tenses quantify over the set of times that include their local evaluation time, (ii) that de re interpretations of tenses are the result of movement that leaves a copy in the embedded clause, and (iii) that Trace Conversion applies to that copy, turning it to mean "the time that is within the set of times that include the local evaluation time (which is identical to the index created by movement)".

Let us now compare (6) to the predictions of previous approaches.

Abusch's ULC-based approach derives a relative component for DAR from the ULC, which prevents a tense node from being assigned a time that is later than its local evaluation time. Therefore, the relative component of de re present and that of de re past would be the same. The ULC-based approach thus predicts (22).

UPPER LIMIT GENERALIZATION:

A de re tense is interpreted as preceding or including the local evaluation time of its base position (AT).

In 4.3 I will argue that (22) is too permissive based on cases where a past-under-past construction is embedded under universal quantification, and that (6) is preferred. 
Ogihara's Copy-based approach suggests that de re readings of tenses are the result of movement that leaves a copy downstairs, which is in line with the Copy theory of movement. Since the semantics of the lower copy is what determines the contribution of the relative component (see footnote 4), the relative component of de re past would require the embedded event to precede AT. Ogihara's Copy-based approach then predicts the following:

\section{TEMPORAL DiRECTIONALITY GENERALIZATION:}

A de re tense is interpreted as:

a. preceding the local evaluation time of its base position if it's PAST.

b. $\quad$ including the local evaluation time of its base position if it's PRES.

In 4.2 I will argue that (23a) does not allow for simultaneous readings of past-underpast in non-SOT languages, whereas given (6) they are naturally explained.

\subsection{Simultaneous readings of past-under-past in Hebrew}

To test whether de re past contributes a relative component of precedence as in (23a) or one of inclusion as in (6) we would want to check what happens with past-under-past sentences: If we could find evidence that de re interpretations of tenses give rise to simultaneous readings, we could have an argument for (6).

Could we argue that the simultaneous reading in (20b) is an instance of a de re past? The answer is no. Many analyses ${ }^{10}$ assume that the embedded past in (20) can be a zero tense, explaining its simultaneous reading through some kind of deletion or SOT rules (see Comrie 1986; Stowell 1995, 2007; Kratzer 1998; Schlenker 1999, 2004 and Grønn \& von Stechow 2010). Abusch (1997) suggests the simultaneous reading of were having in (24) as a motivation for such an explanation:

John decided a week ago that in ten days at breakfast he would say to his mother that they were having their last meal together. (Abusch 1997: 18) ${ }^{11}$

The time of having-last-meal in (24) is normally understood to be simultaneous with the time of having-breakfast and the time of saying, and not to precede any other time we can think of in this sentence: neither the utterance time nor the decision-time. This leads to the conclusion that no treatment of this occurrence of past tense as a real past tense can work, and therefore we need to posit deletion rules for English.

If so, English would be the wrong language to look at when we want to see if $d e$ re past tenses give rise to simultaneous readings, since having deletion rules we might get such readings in another way. What we should do then is consider

10 Though not all; see e.g., Altshuler \& Schwarzschild 2012.

11 The example was originally presented in French in a paper by Kamp and Rohrer. 
languages in which there are no deletion rules, such as Hebrew.

As has been shown by Ogihara \& Sharvit (2012), the fact that Hebrew has no deletion rules is evident in the following Hebrew equivalent to (24), in which the past on axlu ('ate') can only be interpreted as backward-shifted:

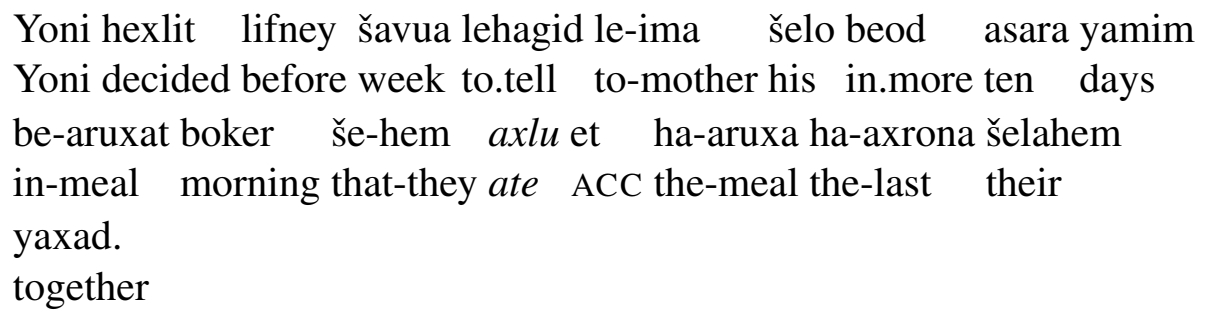

The fact that there is no simultaneous reading available for (26) in the context in (26a) is expected. Surprisingly, however, when the context is as in (26b), a simultaneous reading for (26) is quite natural.

yadati še-Rina hayta be-herayon!

Knew.1sg that-Rina was in-pregnancy!

'I knew that Rina was pregnant!'

a. Context: yesterday I saw Rina with a swollen belly. Sim.: $\boldsymbol{x}$

b. Context: two years ago I saw Rina with a swollen belly. Sim.: $\checkmark$

But if Hebrew has no deletion rules, what could make any simultaneous reading possible? Our only candidate is a de re account. The simultaneous reading of (26) in the context in (26b) could be explained with a de re LF, if we assume (6). But as Ogihara \& Sharvit (2012) pointed out, within the Copy-based approach we cannot derive simultaneous readings for de re past because of (23a), thus it cannot explain simultaneous readings of past-under-past in non-SOT languages such as Hebrew.

Moreover, (26) shows that a de re analysis of tenses is needed. ${ }^{12}$ First, what determines the availability of a simultaneous reading for (26) is the distance from the utterance time, which already points at the direction of an interpretation that involves indexicality, which is what a de re interpretation would yield. Second, consider the well-observed contrast in (3), repeated here:

Double access:

a. Yesterday, John thought that Mary is pregnant.

b. \#Two years ago, John thought that Mary is pregnant.

12 See Ogihara \& Sharvit 2012 for another instance of a simultaneous reading of past-under-past in Hebrew that involves a mistake of the attitude holder regarding the time he is in, which also points at the direction of a de re analysis. 
There is a clear correlation between (26) and (3): A simultaneous reading for past-under-past in Hebrew requires a setup in which an English present-under-past wouldn't be accepted, and vice versa: English present-under-past requires a setup in which a simultaneous reading for past-under-past in Hebrew wouldn't be accepted.

This is reminiscent of the correlation between past and present in matrix clauses: Mary was pregnant isn't normally accepted when Mary is pregnant is true.

Assuming that both DAR and simultaneous readings of past-under-past in Hebrew are instances of a de re interpretation of a tense, the correlation between (26) and (3) is expected. ${ }^{13}$ But if one wants to deny the need for de re tenses and explain the DAR using an involved semantics for English present which incorporates both an indexical component and a relative component (as in Gennari 2003; Altshuler \& Schwarzschild 2013 and Bary \& Altshuler 2015), one would have to say something similar about Hebrew past to account for that correlation. However, there is no evidence that Hebrew past should have an indexical component in its semantics.

\subsection{Functional readings of tenses}

The prediction of the ULC-based approach in (22) is compatible with simultaneous readings for de re past, so it can explain the Hebrew data in (26). But (22) predicts also backward-shifted readings for de re past, against which I argue in this section.

Before I argue against (22), a word about time concepts is in order. Abusch (1997) utilizes Lewis' acquaintance relations for tenses, or in Heim's (1994) terminology: time concepts. The idea is that a de re interpretation of a tense involves reference to some time, and a time concept by which the attitude holder (John in our examples) can describe this time to himself. Time concepts can be "yesterday", "now", "tomorrow", "this year", or "last time the lights went out". Given, for example, the time concept "yesterday", the de re interpretation of (20) is roughly (27) (where (27a) represents an indexical component and (27b) a relative component):

The time of which John believed Mary to be pregnant is such that:

a. From the speaker's perspective it precedes the "now". Indexical c.

b. From John's perspective it's "yesterday". Relative c.

The ULC-based approach then rules out using time concepts such as "tomorrow" or "a year from now", because they would lead to a violation of the ULC. ${ }^{14}$

Consider now the example in (28), in which a past-under-past construction is

13 The exact mechanism by which this correlation should be derived is left to be spelled out. Hopefully, this would fall out from an analysis of why a PAST- $\phi$ sentence has a non-PRES- $\phi$ inference. See Altshuler \& Schwarzschild 2012 and references therein.

14 An interesting question arises regarding temporally neutral time concepts such as “on Bill's 40th birthday". Following Heim (1994: fn. 28), Bary \& Altshuler (2015) discuss the scenario in (iii): 
embedded under universal quantification over individuals. Just like any other pastunder-past sentence in English, it has two readings: a backward-shifted reading as in (28a) and a simultaneous reading as in (28b). Importantly, (28a) is a reading of (28) even with a functional meaning, i.e., if every doctor had another past-time in mind. However, there is no 'mixed' functional reading for (28) in which for some doctors it was a past-time and for some doctors it was a present-time, as in $(28 \mathrm{c}) .{ }^{15}$

Every doctor thought Mary was pregnant.

a. Every doctor thought: "Mary was pregnant". Backward-shifted

b. Every doctor thought: "Mary is pregnant". Simultaneous

c. *Some doctors thought: "Mary was pregnant", and Some doctors thought: "Mary is pregnant".

Mixed

Recall that the ULC rules out time concepts that involve future reference, such as "tomorrow". On the face of it, then, the time concept in (29) should be allowed.

At the time I am Mary's doctor, be it now or before.

Suppose that Mary was seriously injured, and after being brought to the hospital, the doctors at the E.R., Sue and Sally, were consulting each other. Sue was Mary's doctor at that time, and Sally was Mary's doctor two years before that. For some reason, it was relevant for Mary's treatment whether she had been pregnant at any time in her life. Sue thought: "Sure, she is pregnant now", and Sally thought: "She was pregnant when I was her doctor, two years ago". Following the ULC-based approach, the functional de re reading of (28) using the time concept in (29) should give rise to the

(iii) John thinks Bill's 40th birthday is in the past and that Mary was pregnant on that day. Bill's 40th birthday is in fact the day of John's thinking, which is today.

In this context, (1) is infelicitous. However, the ULC-based approach predicts it to be felicitous: The indexical component of DAR requires inclusion of UT (in reality), and the time of Bill's 40th birthday does include the utterance time; the relative component provided by the ULC requires Bill's 40th birthday not to be later than AT (in John's mind), and it isn't.

Heim (1994) therefore suggests that there is a prohibition on temporally neutral time concepts. However, Bary \& Altshuler (2015) show that once the relative component of DAR requires that the time of Mary's pregnancy include AT rather than include or precede it, this prohibition is redundant and temporally neutral time concepts become harmless. Note that this is in line with (6).

15 I thank Danny Fox for pointing out the relevance of such examples. The same argumentation can be done with quantification over times as in (iv) and with ellipsis as in (v).

(iv) In the last few years, every time I met John he told me that he was sick.

(v) Yesterday I met John and Mary. She told me she was sick, and he did too. 
reading in $(28 \mathrm{c})$ in this scenario. However, no such reading is available. ${ }^{16}$

In other words, this situation is compatible with the predicted functional de re reading for (28) given the time concept in (29), which can be described as follows:

For each doctor, the time of which she believed Mary to be pregnant is s.t.:

a. From the speaker's perspective it precedes the "now". Indexical c.

b. From that doctor's perspective it's the time of her being Mary's doctor (which is not later than her "now"). Relative c.

Given (6) no mixed reading is predicted: Since a de re past yields no backwardshifted reading, it yields no mixed simultaneous and backward-shifted one as well.

Can we maintain the ULC and rule out (28c)? A few ideas may come to mind:

i. Functional readings are not possible for tenses interpreted de re. That is, the de re past cannot be bound by the universal quantification. This would indeed solve the problem, but it is not clear why that would be the case: what would allow such binding for non-de re tenses and prevent it for de re tenses?

ii. Temporally neutral time concepts are ruled out, as suggested by Heim (1994: fn. 28). First, for that to help here we would have to say that the time concept in (29) counts as temporally neutral even though it does encode at least some temporal relation. Second, as Bary \& Altshuler (2015) show, ruling out temporally neutral time concepts is not necessary if the relative component of DAR requires inclusion (see footnote 14).

These are indeed possible refutations of the argument presented here, but as I have shown none of them is trivial. Combined with the stipulative nature of the ULC, the data presented here might be a good-enough reason to rethink it.

\section{Concluding remarks}

To conclude, the current proposal has several advantages over previous de re analyses. First, the ULC assumed by Abusch (1997) can be dispensed with, as in Ogihara

16 It should be noted that the data here are problematic for pragmatic accounts of SOT phenomena such as Gennari 2003. According to Gennari, simultaneous readings of past-under-past in English do not require a different representation than backward-shifted readings, but result from a real embedded past tense and a "superinterval property" of stative predicates which allows a past state to stretch up to the present. Since the backward-shifted reading and the simultaneous reading are derived from the same LF in this analysis, it is not clear why that LF would not admit a mixed reading of the two, as in (28c). Even though Altshuler \& Schwarzschild (2013) also assume only one representation for English past-under-past sentences, their analysis differs from Gennari's in important respects. Because of that, the question of the vulnerability of Altshuler \& Schwarzschild's analysis to this argument is more subtle and requires another discussion, which I will not pursue here. 
1989. Second, simultaneous readings of past-under-past in Hebrew and the DAR of present-under-past in English are both accounted for as instances of a de re interpretation of tenses, in contrast with Ogihara's Copy-based approach. Third, the unavailability of mixed functional readings of past-under-past sentences is naturally accounted for, unlike in Abusch's ULC-based approach.

As has been shown in the last section, these advantages result from the fact that the current proposal predicts (6) whereas previous analyses do not.

One may ask what alternatives we have, if we are convinced that a de re analysis of tenses is needed and that the Inclusion Generalization in (6) is correct. For example, my analysis relies heavily on the assumptions that tenses are quantificational and that they can move: The interplay between the inner structure of the quantificational tenses and the application of Trace Conversion to moved tenses enabled me to predict (6). Is there a way to do without these assumptions?

For now, I can only think of one possible alternative, which assumes no tense movement. Suppose that tenses are pronominal and have the following semantics (I discuss here only PAST tenses for brevity, but this also extends naturally to PRES).

$$
\llbracket \mathrm{PAST}_{i, j} \rrbracket^{g} \text { is defined only if } g(i)<g(j) \text {. When defined, } \llbracket \mathrm{PAST}_{i, j} \rrbracket^{g}=g(i)
$$

When the second index of tenses is locally bound, i.e., when they are evaluated with respect to the local evaluation time, nothing special needs to be said.

$$
\lambda t_{1} \text { John PAST } 2,1 \text { think that } \lambda t_{3} \text { Mary PAST }_{4,3} \text { be-pregnant }
$$

The problem begins where the second index of a tense is non-locally bound, namely if instead of $\mathrm{PAST}_{4,3}$ in (32) we would have $\mathrm{PAST}_{4,1}$. Let us adopt a concept-generator mechanism as in Percus \& Sauerland 2003 and Charlow \& Sharvit 2014, and assume that tenses that are non-locally bound are interpreted through the application of a concept generator which is syntactically realized, as in (33).

$$
\lambda t_{1} \text { John PAST } 2,1 \text { think that } \lambda G_{8} \lambda t_{3} \text { Mary }\left[G_{8} \mathrm{PAST}_{4,1}\right] \text { be-pregnant }
$$

$G_{8}$ provides a suitable acquaintance relation between John and the time $g(4)$. Now, what if we assumed that acquaintance relations about times are so restricted that any acquaintance relation which does not involve presentness is ruled out? In other words, the only time with which we are sufficiently acquainted is our "now". With both the past and the future we are not sufficiently acquainted. So "today" and "this month" are fine descriptions, but "yesterday" and "tomorrow" are not.

In a sense, this would be both an Upper Limit and a Lower Limit constraint. But differently from Abusch's (1997) ULC, it will not be done by constraining the assignments of tense nodes, but rather by constraining acquaintance relations. Therefore it will not affect cases of tenses that are locally bound in which no 
acquaintance relations are involved, but only de re tenses. However, similarly to the ULC, such a restriction on acquaintance relations seems unmotivated.

One possible motivation to prefer this kind of analysis over the one I suggested in Section 3 is that the way PAST is defined in (14b) is problematic. This definition of PAST renders it a non-conservative quantifier, i.e., (34a) and (34b) are not equivalent. (34b) is in fact contradictory: $t$ should be both in $T$ and at the same time before some time in $T$. Given that $T$ is the set of times that include the evaluation time, there is no time in $T$ which precedes another time in $T$, so this yields a contradiction.

$$
\begin{array}{ll}
\text { a. } & \llbracket \operatorname{PAST} \rrbracket(T)(P)=1 \text { iff } \exists t\left[\exists t^{\prime}\left[T\left(t^{\prime}\right) \wedge t<t^{\prime}\right] \wedge P(t)=1\right] \\
\text { b. } & \llbracket \operatorname{PAST} \rrbracket(T)(T \cap P)=1 \text { iff } \exists t\left[\exists t^{\prime}\left[T\left(t^{\prime}\right) \wedge t<t^{\prime}\right] \wedge T(t) \wedge P(t)=1\right]
\end{array}
$$

This is problematic for local movements of PAST: In cases where two copies of PAST appear in the scope of the same local evaluation time, the result would be a fatal presupposition failure: The lower copy will presuppose inclusion of the evaluation time whereas the higher copy will assert precedence with respect to it.

It has been suggested (Fox 2002: fn. 8, a.o.) that conservativity of natural language determiners follows from the Copy theory of movement: Given the Copy theory, non-conservative quantifiers would lead to trivial meanings. It has been noted by Sportiche (2005), Hallman (2012) and Romoli (2015), that once we allow two copies to be evaluated with respect to two different worlds, this connection breaks down and non-conservative quantifiers may give rise to non-trivial meanings. This is essentially what is assumed here: The two copies of PAST must be interpreted with respect to different times, otherwise they would lead to trivial meanings.

Relatedly, it is assumed here that two copies can have two different binders: One copy can be bound by the matrix local evaluation time and the other by the embedded one. One may ask whether this is natural, and if we could find anything like that in the nominal domain. I have no good answers to these questions. I thank Danny Fox and Uli Sauerland for pointing that out, and leave it for further discussion.

Finally, the motivation of Ogihara (1989) for his Temporal Directionality Isomorphism, represented here in (23), is data from Japanese in which there are no simultaneous readings for past-under-past. The solution Ogihara \& Sharvit (2012) suggest involves making the question of whether movement leaves a Copy behind subject to crosslinguistic variation, a route which I tried to avoid.

To the extent that there are indeed no such readings in Japanese, in the view adopted here it means that the structure where past has QRed is blocked. Note that for Hebrew there is anyway still a need for an account of when the QRed structure is available for past-uner-past sentences, namely the conditions under which a simultaneous reading is available (see footnote 13); and for English too, the unavailability of a present-under-past in-situ needs to be explained (see footnote 2). 
Bar-Lev

\section{References}

Abusch, Dorit. 1997. Sequence of tense and temporal de re. Linguistics and Philosophy 20(1). 1-50. doi:10.1023/A:1005331423820.

Altshuler, Daniel \& Roger Schwarzschild. 2012. Moment of change, cessation implicatures and simultaneous readings. In Emanuel Chemla, Vincent Homer \& Gregoire Winterstein (eds.), Sinn und Bedeutung (SuB) 17, 45-62. http: //semanticsarchive.net/sub2012/.

Altshuler, Daniel \& Roger Schwarzschild. 2013. Correlating cessation with double access. In Maria Aloni, Michael Franke \& Floris Roelofsen (eds.), 19th Amsterdam Colloquium, 43-50. http://www.illc.uva.nl/AC/AC2013/Proceedings/.

Bary, Corien \& Daniel Altshuler. 2015. Double access. In Eva Csipak \& Hedde Zeijlstra (eds.), Sinn und Bedeutung (SuB) 19, 89-106.

Charlow, Simon \& Yael Sharvit. 2014. Bound 'de re' pronouns and the LFs of attitude reports. Semantics and Pragmatics 7(3). 1-43. doi:10.3765/sp.7.3.

Comrie, Bernard. 1986. Tense in indirect speech. Folia linguistica 20(3-4). 265-296. doi:10.1515/flin.1986.20.3-4.265.

von Fintel, Kai \& Irene Heim. 2011. Intensional semantics. Manuscript, Massachusetts Institute of Technology, Spring 2011.

Fox, Danny. 2002. Antecedent-contained deletion and the copy theory of movement. Linguistic Inquiry 33(1). 63-96. doi:10.1162/002438902317382189.

Gennari, Silvia P. 2003. Tense meanings and temporal interpretation. Journal of Semantics 20(1). 35-71. doi:10.1093/jos/20.1.35.

Grønn, Atle \& Arnim von Stechow. 2010. Complement tense in contrast: The SOT parameter in Russian and English. Oslo Studies in Language 2(1). 109-153.

Hallman, Peter. 2012. Prospects for a syntactic analysis of conservativity. UCLA Working Papers in Linguistics 17. 103-108.

Heim, Irene. 1994. Comments on Abusch's theory of tense. In Hans Kamp (ed.), Ellipsis, Tense and Questions, Dyana-2, Deliverable R2.2.B.

Jespersen, Otto. 1924. The philosophy of grammar. London: Allen and Unwin.

Klecha, Peter. 2014. Modality and embedded temporal operators. Manuscript, Ohio State University.

Kratzer, Angelika. 1998. More structural analogies between pronouns and tenses. In Devon Strolovitch \& Aaron Lawson (eds.), Semantics and Linguistic Theory (SALT) 8, 92-110. Ithaca, NY: Cornell University. doi:10.3765/salt.v8i0.2808.

Kusumoto, Kiyomi. 2005. On the quantification over times in natural language. Natural Language Semantics 13(4). 317-357. doi:10.1007/s11050-005-4537-6.

Ogihara, Toshiyuki. 1989. Temporal reference in English and Japanese. University of Texas at Austin PhD dissertation.

Ogihara, Toshiyuki \& Yael Sharvit. 2012. Embedded tenses. In Robert I. Bin- 
De re tenses and trace conversion

nick (ed.), Handbook of Tense and Aspect, 638-668. Oxford University Press. doi:10.1093/oxfordhb/9780195381979.013.0022.

Partee, Barbara Hall. 1973. Some structural analogies between tenses and pronouns in English. The Journal of Philosophy 70(18). 601-609. doi:10.2307/2025024.

Percus, Orin. 2000. Constraints on some other variables in syntax. Natural Language Semantics 8(3). 173-229. doi:10.1023/A:1011298526791.

Percus, Orin \& Uli Sauerland. 2003. On the LFs of attitude reports. In Matthias Weisgerber (ed.), Sinn und Bedeutung (SuB) 7, 228-242. http://semanticsarchive. net/Archive/TE3NGV1Y/.

Romoli, Jacopo. 2015. A structural account of conservativity. Semantics-Syntax Interface 2(1). 28-57.

Schlenker, Philippe. 1999. Propositional attitudes and indexicality: A cross categorial approach. Massachusetts Institute of Technology, Department of Linguistics and Philosophy, PhD dissertation.

Schlenker, Philippe. 2004. Sequence phenomena and double access readings generalized: Two remarks on tense, person, and mood. In Jacqueline Guéron \& Alexander Lecarme (eds.), The Syntax of Time, Cambridge, MA: MIT press.

Sportiche, Dominique. 2005. Division of labor between merge and move: Strict locality of selection and apparent reconstruction paradoxes. Manuscript, UCLA. von Stechow, Arnim. 1995. On the proper treatment of tense. In Mandy Simons \& Teresa Galloway (eds.), Semantics and Linguistic Theory (SALT) 5, 362-386. Ithaca, NY: Cornell University.

Stowell, Tim. 1995. What do the present and past tenses mean? In Pier Marco Bertinetto, Valentina Bianchi, James Higginbotham \& Mario Squartini (eds.), Temporal Reference: Aspect and Actionality 1, 381-396. Torino: Rosenberg \& Sellier.

Stowell, Tim. 2007. The syntactic expression of tense. Lingua 117(2). 437-463. doi:10.1016/j.lingua.2005.08.003.

Moshe E. Bar-Lev

Language, Logic and Cognition Center

The Hebrew University of Jerusalem

Mount Scopus

91905 Jerusalem

Israel

mosheel.levin@mail.huji.ac.il 